Proceedings

\title{
Antiviral activity and physicochemical properties of 4-Amino-phenyl-quinazoline derivatives for Bovine Viral Diarrhea Virus (BVDV) ${ }^{\dagger}$
}

\author{
Gabriela A. Fernández ${ }^{1, *}$, Daniela M. Fidalgo ${ }^{1}$, Rocio A. Rosas ${ }^{2}$, Leandro Battini ${ }^{1}$, Eliana Castro \\ 3, Lucia V. Cavallaro ${ }^{2}$, Mariela Bollini ${ }^{1}$. \\ 1 CONICET, Centro de Investigaciones en Bionanociencias (CIBION). Buenos Aires, Argentina; \\ mariebollini@gmail.com \\ 2 Universidad de Buenos Aires, Facultad de Farmacia y Bioquímica, Cátedra de Virología. Buenos Aires, \\ Argentina; luciacavallaro@yahoo.com.ar \\ 3 CONICET, Universidad de Buenos Aires. Facultad de Farmacia y Bioquímica, Cátedra de Virología. IVIT, \\ INTA. Buenos Aires, Argentina; elianacastro82@gmailcom.ar \\ * Correspondence: araceli.fernandez@cibion.conicet.gov.ar; Tel.: +54-011-4899-5500
}

\begin{abstract}
Bovine Viral Diarrhea Virus (BVDV) is a pestivirus whose infection in cattle is globally distributed being endemic in many countries. We have identified potential molecules that dock into the allosteric binding pocket of BVDV RdRp via structure-based virtual screening approach. Five of these compounds resulted active against BVDV in vitro. Among them, $\mathrm{N}$-(2-morpholinoethyl)-2-phenylquinazolin-4-amine $\left(\mathrm{EC}_{50}=9.68 \pm 0.49 \mu \mathrm{M}\right)$, was selected to perform different chemical modifications. Between twenty-seven derivatives, seven of them showed improved antiviral activity. Compound 2-(4-(2-phenylquinazolin-4-yl)piperazin-1-yl)ethanol afforded the best values of antiviral activity and selectivity index (SI) and their physicochemical properties were examined in vitro, in terms of solubility and stability.
\end{abstract}

Keywords: Bovine Viral Diarrhea Virus, Antiviral, RdRp protein.

\section{Introduction}

Bovine Viral Diarrhea Virus 1 (BVDV), named Pestivirus A from 2017 International Committee on Taxonomy of Viruses report belongs to the Pestivirus genus of the family Flaviviridae [1]. BVDV is an important pathogen of cattle worldwide with significant economic consequences [2].

The main impact of BVDV in a herd is in the bovine reproductive cycle. The consequences are mainly determined by the gestational age of the fetus at the time of infection with this virus, generating embryonic death in early stages, alterations of heat, as well as abortions throughout the gestation. Infection during pregnancy can also trigger congenital malformations, which occur in different types and degrees. It may lead to a wide array of clinical signs from subclinical to severe acute hemorrhagic syndrome. BVDV also causes immunosuppression, which increases the severity of the clinical picture. BVDV infection of seronegative and pregnant females during the first 40-120 days of pregnancy may lead to the birth of persistently infected (PI) calves. They remain infected for life, ensuring the persistence of BVDV in the herd if they are not removed immediately after identification [3].

In Argentina, serological surveys showed values of individual seroprevalence ranging from 32 to $100 \%$. The economic impact of BVDV in different types of establishments has led several regions of the world to initiate eradication plans, which in some cases are still under development. The control of BVDV infections combines vaccination, which is not mandatory in some countries, and the detection and removal of persistently infected animals [3]. The vaccination has a disadvantage in terms of the time it takes to activate the immune response of the animal and the increase in the 
antibody titer needed to protect against an infection. For this reason, there is a necessity to have effective and rapid control, and the use of antivirals could be useful for this purpose.

RNA-dependent RNA polymerase ( $R d R p)$ is a proven target for antiviral drug development [4]. In our previous work, we identified potential molecules that can dock into the allosteric binding pocket of BVDV RdRp via a structure-based virtual screening approach. From this study, we obtained a series of structurally and functionally diverse compounds which resulted active against BVDV in vitro, and from biological assays displayed $\mathrm{EC}_{50}$ values in the sub and low-micromolar range [5]. From these, $\mathrm{N}$-(2-morpholinoethyl)-2-phenylquinazolin-4-amine $\left(\mathrm{EC}_{50}=9.68 \pm 0.49 \mu \mathrm{M}\right)(\mathbf{1})$ (Figure 1) was selected to perform different chemical modifications in order to improve its antiviral profile. In this work, we present our results for the derivates obtained from $\mathbf{1 .}$

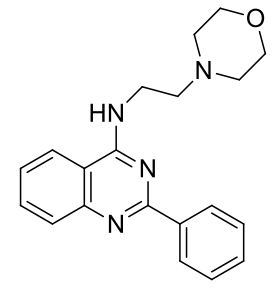

Figure 1. Structure of compound 1.

\section{Materials and Methods}

\subsection{Chemistry}

\subsubsection{Synthesis of 2-phenylquinazoline derivates}

We prepared a range of quinazoline analogs according to previously described procedures (Figure 2). Compounds 1-1.6 were synthesized as Bollini and coworkers previously reported [6]. The compounds 1.7-1.9, 1.11-1.26 were prepared through four steps (Scheme 1) [6-10]. Briefly, the compounds were obtained by reaction between isatoic anhydride and ammonia in the presence of trimethylamine in a mixture acetonitrile:methanol (1:1), to generate o-aminobenzamide (I, 41-53\%). Quinazolinone scaffolds (II) were reached through the reaction between I and several benzaldehydes with sodium hydrogensulfite in DMAC (43-63\%). Chlorination of 4-quinazolinones with $\mathrm{POCl}_{3}$ allowed to obtain 4-chloro-2-phenylquinazoline derivates (IIIa-d, 70-76\%). The final products (1.1-1.26) were obtained by aromatic nucleophilic substitution reaction of amines or anilines in the presence of DIPEA in n-butanol under reflux conditions. The compounds were purified by preparative TLC in mixtures of DCM:MeOH (9:1) to give the products in 28-84 \% yield. Compound IIe was obtained by reaction between 2-amino-4-chlorobenzoic acid and formamide at reflux, followed by recrystallization from acetonitrile to give the product in $80 \%$ yield (Scheme 2). The subsequent step was performed with $\mathrm{SOCl}_{2}$ at reflux to yield IIIe $(83 \%)$, to continue with the SNAr reaction with 2-morpholinoethan-1-amine to obtain 1.10. Starting from IIIa, compound $\mathbf{1 . 2 7}$ was obtained by SNAr reaction with 2-morpholinoethanol and sodium hydride in anhydrous THF (54\%) (Scheme 3). 
<smiles>Clc1ccc2c(I)ncnc2c1</smiles><smiles>CCNCCN1CCOCC1</smiles><smiles>CCNCCN1CCCCC1</smiles>

1.20<smiles>O=[N+]([O-])c1ccc(-c2nc([Tl])c3ccccc3n2)cc1</smiles><smiles>CN1CC2CN(C)CC2C1</smiles><smiles>CN1CCN(C)CC1</smiles><smiles>Clc1ccc(-c2nc([Tl])c3ccccc3n2)c(Cl)c1</smiles><smiles>NCCN1CCOC1</smiles>

1.19<smiles>CN1CCN(C)CC1</smiles><smiles>c1ccc2nc(-c3ccc4c(c3)OCCC4)ncc2c1</smiles>

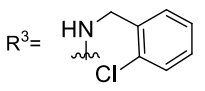

1.2<smiles>CCCN1CCN(CCO)CC1</smiles>

HO<smiles>CC(C)CCN(CCO)CCN1CCCCC1</smiles><smiles>c1ccc(-c2n[14cH]c3ccccc3n2)cc1</smiles><smiles>COc1ccc(CNC=NCc2ccc(C)cc2)cc1</smiles>

1.1

1.3<smiles>CN1CCN(CCO)C1</smiles><smiles>NCCN1CCCCC1</smiles>

1.5<smiles>CC(C)(C)c1cccc(CN)c1C(C)(C)C</smiles>

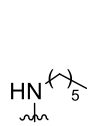<smiles>C1CCN2CCCN2CC1</smiles>
$\mathrm{HN}^{2}+\mathrm{N}^{3} \mathrm{~N}^{-}$<smiles>CC1CCN(Cc2ccccc2)CC1</smiles><smiles>CC1(C)CC(N)CC1(C)C</smiles><smiles>CCNCCN1CC(C)OC1C</smiles><smiles>CC1CN(C)CC1C</smiles><smiles>c1ccc2cnccc2c1</smiles><smiles>COCCN1CCOC1</smiles>

Figure 2. Compounds synthesized from a quinazoline core.<smiles>[R]c1ccc2c([R])nc([R])nc2c1</smiles>
la: $\mathrm{R}^{1}=\mathrm{H}$
Ila y IIla: $R^{1}=H ; R^{2}=P h$
lb: $\mathrm{R}^{1}=\mathrm{Cl}$
Ilb y IIlb: $R^{1}=H ; R^{2}=(3,4-$ methylenedioxy $) P h$
Ilc y IIIc: $R^{1}=H ; R^{2}=2,4-d i C I P h$
Ild y IIId: $\mathrm{R}^{1}=\mathrm{H} ; \mathrm{R}^{2}: 4-\mathrm{NO}_{2} \mathrm{Ph}$

Reaction conditions: a) $\mathrm{NH}_{4} \mathrm{OH}, \mathrm{NEt}_{3}, \mathrm{H}_{2} \mathrm{O}: \mathrm{ACN}$, r.t., 2 h. b) $\mathrm{R}^{2} \mathrm{CHO}, \mathrm{NaHSO}_{3}$, DMAC, $150^{\circ} \mathrm{C}, 2 \mathrm{~h}$.

c) $\mathrm{POCl}_{3}$, reflux, 3 h. d) $\mathrm{R}^{3}=$ amines, DIPEA, BuOH, reflux, overnight.

Scheme 1. General procedure for the synthesis of 2-phenylquinazoline derivates.<smiles>Nc1cc(Cl)ccc1C(=O)O</smiles>

Ile

IIIe

Reaction conditions: e) $\mathrm{HCONH}_{2}, 150^{\circ} \mathrm{C}, 24$ h. f) $\mathrm{SOCl}_{2}$, reflux, 2 h.

Scheme 2. Preparation of intermediates for the synthesis of compound 1.10. 


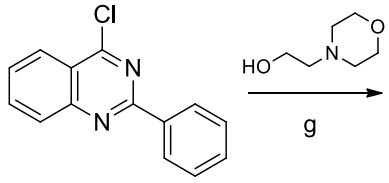

IIla

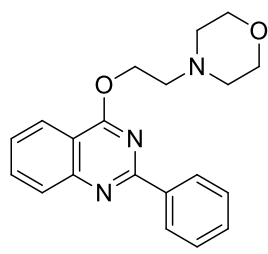

1.27

Reaction conditions: g) $\mathrm{NaH}$, anh. THF, $80^{\circ} \mathrm{C}, 4 \mathrm{~h}$.

Scheme 3. Last step for the synthesis of compound 1.27.

\subsection{Biological Assays}

\subsubsection{Cells and virus}

Madin Darby bovine kidney cells (MDBK NBL-1; ATCC CCL-22) were grown in Minimal Essential Medium (EMEM), supplemented with $10 \%$ biotechnological fetal bovine serum (Internegocios, Argentina) (GM) at $37{ }^{\circ} \mathrm{C}$ and $5 \% \mathrm{CO}_{2}$. Bovine viral diarrhea virus (BVDV) type 1 NADL strain, cytopathic biotype (BVDV-1, ATCC VR 534) was provided by Dr. Laura Weber (INTA Castelar, Argentina).

\subsubsection{Cytotoxicity and Anti-BVDV assays}

- Cytotoxicity assay: MDBK cells were seeded in microplates at a density of $1 \times 10^{4}$ cells per well of a 96-well plate in GM. After $24 \mathrm{~h}$, serial dilutions of the test compounds, made in E-MEM supplemented with donor horse serum (DHS, Gibco) (IM), were added. Cells were allowed to proliferate for 3 days at $37^{\circ} \mathrm{C}$, after which the cell viability in the culture was determined by means of MTS/PMS method (Promega). The yield of formazan product is proportional to the number of living cells. After $3 \mathrm{~h}$ at $37{ }^{\circ} \mathrm{C}$, the absorbance was determined at $490 \mathrm{~nm}$. The $50 \%$ cytotoxic concentration $\left(\mathrm{CC}_{50}\right)$ was defined as the concentration of compound that inhibited the proliferation of exponentially growing cells by $50 \%$ and was calculated by interpolation from dose-response curves.

- Anti-BVDV assay: MDBK cells were seeded in microplates (96 wells) at a density of $1 \times 10^{4}$ cells per well in GM. Following $24 \mathrm{~h}$ of incubation at $37^{\circ} \mathrm{C}$, medium was removed, monolayers were washed twice with PBS and infected with BVDV with an inoculum that resulted in a greater than $80 \%$ of cytopathic effect after 3 days of incubation at $37^{\circ} \mathrm{C}$ (approximately MOI 0.01). Then, serial dilutions of the test compounds in IM were added. Mock-infected cells and mock-treated infected cells were included as controls in each assay plate. After 3 days, medium was removed, cell monolayers were washed twice with PBS and IM supplemented with MTS/PMS solution was added to each well. The absorbance of each well was read at $490 \mathrm{~nm}$. The $50 \%$ effective concentration (EC 50$)$ was defined as the concentration of compound that offered $50 \%$ protection of the cells against virus-induced CPE and was calculated by interpolation from dose-response curves.

\subsection{Physicochemical Properties}

\subsubsection{Solubility Study Protocol}

Solubility was determined by UV-Visible spectrometry in simulated gastric fluid (SGF, pH 1.2), simulated intestinal fluid (SIF, pH 6.8) and phosphate buffered saline (PBS, pH 7.4), employing the shake-flask method.

For each media, a mixture of $1.0 \mathrm{mg}$ of compound in $1 \mathrm{~mL}$ of the buffer solutions (pH 1.2, 6.8 and 7.4) were incubated at $37^{\circ} \mathrm{C}$ over $24 \mathrm{~h}$. After this period, the stirring was turned off and the mixtures keep at the same temperature over $24 \mathrm{~h}$. The samples were filtered through a $0.22-\mu \mathrm{m}$ syringe-driven filters (FPE-204-013). The filtered solutions were diluted with buffer:MeOH (1:1) $1 / 100,1 / 50$ and 1/25 respectively. UV-Visible spectrums were measured in a range of 500-200 $\mathrm{nm}$ 
using a quartz cuvette. The absorption was determined from linearity $(2.5-40 \mu \mathrm{g} / \mathrm{mL})$ at $331 \mathrm{~nm}$. For each medium, the samples were performed in triplicate.

\subsubsection{Stability Analysis Protocol}

Stock solutions of test compounds were prepared at a concentration of $10 \mathrm{mM}$ in DMSO. The stock solution was diluted in DMSO to $1 \mathrm{mM}$. The mouse and bovine plasma was diluted to $80 \%$ with PBS. The reactions were initiated by the addition of the test compounds to the preheated plasma solution (final concentration: $50 \mathrm{mM}$ ). Sampleswere incubated in a shaking water bath at $37{ }^{\circ} \mathrm{C}$ and conducted in triplicate. Samples $(50 \mathrm{~mL})$ were taken at 0, 15, 30, 60, 90, $120 \mathrm{~min}$ and 200mL of cold acetonitrile containing the internal standard (warfarin) was added to deproteinize the plasma. The samples were vortexed for $1 \mathrm{~min}$ and then centrifugated at $4{ }^{\circ} \mathrm{C}$ for $15 \mathrm{~min}$ at $14000 \mathrm{rpm}$. Enalapril and salicylaldehyde isonicotinoyl hydrazine $(\mathrm{SIH})$ [11] were used as positives controls incubation for mouse and bovine plasma, respectively. The supernatant was collected, diluted in methanol: water (50:50) and analyzed by HPLC-MS. The quantification was based on the peak area ratio of the test compound vs. the internal standard.

The HPLC-MS analysis was performed using a Waters Alliance e2695 system fitted with a Phenomenex Kinetex ${ }^{\circledR}$ XB-C18 $(150 \times 4.6$ mm, $5 \mu \mathrm{m}$ particle size), coupled to a Waters SQD2 single quadrupole mass spectrometer with an electrospray ionization (ESI) source. Gradient elution was utilized in the chromatographic separation method using $40 \%$ water and $0.1 \%$ acetic acid (mobile phase A), 40\% methanol (mobile phase B), with the following program: 0-3 $\min 40 \%$ B; $3-7$ min 40-90\% $\mathrm{B} ; 7-20 \mathrm{~min} 90 \%$. The flow rate was constant at $0.35 \mathrm{~mL} \mathrm{~min}^{-1}$. After each sample injection, the gradient was returned to its initial conditions in $16 \mathrm{~min}$. The injection volume was $5 \mu \mathrm{L}$. The column temperature was $35{ }^{\circ} \mathrm{C}$. The mass spectrometer was operated in positive ion mode with a probe capillary voltage of $2.5 \mathrm{kV}$. The sampling cone voltage was set to $35.0 \mathrm{~V}$. The source and desolvation gas temperatures were set at $150{ }^{\circ} \mathrm{C}$ and $350{ }^{\circ} \mathrm{C}$, respectively. The nitrogen gas desolvation flow rate was $600 \mathrm{~L} \mathrm{~h}^{-1}$ and the cone gas flow rate was $10 \mathrm{~L} \mathrm{~h}^{-1}$. The mass spectrometer was calibrated across the range of $\mathrm{m} / \mathrm{z} 20-2023$ with a sodium and cesium iodide solution. Data were acquired in scan mode with a scan duration of $0.2 \mathrm{~s}$, and in SIR mode with unit resolution. Data acquisition and processing were carried out using MassLynx, version 4.1 software.

\section{Results and Discussion}

Different chemical modifications were done on 1 at positions C-2, C-4 and C-7 of quinazoline scaffold, in order to improve its antiviral profile. The results are summarized in Table 1. Twenty-seven derivatives were obtained, six of which showed improved antiviral activity. Five compounds, 1.8-1.12, showed better selectivity indexes (SI) than the original molecule, where compound $\mathbf{1 . 8}$ presented a SI ten times higher than that of $\mathbf{1}$. Compounds that presented less than 50 $\%$ of inhibition of CPE at MNCC were considered inactives.

Table 1. Cytotoxicity and anti-BVDV activity of Compound 1 derivatives.*

\begin{tabular}{ccccc}
\hline Compound & $\begin{array}{c}\mathrm{CC}_{50} \pm \mathrm{SD} \\
(\boldsymbol{\mu M})\end{array}$ & $\begin{array}{c}\text { MCNC } \\
(\boldsymbol{\mu M})\end{array}$ & $\begin{array}{c}\mathrm{CE}_{50} \pm \mathrm{DS} \\
(\boldsymbol{\mu M})\end{array}$ & SI \\
\hline $\mathbf{1}$ & $55.90 \pm 8.20$ & 12.5 & $9.68 \pm 0.49$ & 5.77 \\
$\mathbf{1 . 8}$ & $64.15 \pm 4.65$ & 25.0 & $1.24 \pm 0.65$ & 51.73 \\
$\mathbf{1 . 9}$ & $34.45 \pm 1.85$ & 12.5 & $1.47 \pm 0.04$ & 23.44 \\
$\mathbf{1 . 1 0}$ & $65.67 \pm 7.71$ & 25.0 & $2.84 \pm 0.85$ & 23.21 \\
$\mathbf{1 . 1 1}$ & $21.03 \pm 5.63$ & 12.5 & $0.92 \pm 0.11$ & 22.86 \\
$\mathbf{1 . 1 2}$ & $56.98 \pm 0.01$ & 19.0 & $4.57 \pm 0.97$ & 12.47 \\
$\mathbf{1 . 1 4}$ & $7.38 \pm 0.03$ & 3.12 & $1.37 \pm 0.27$ & 5.39 \\
\hline
\end{tabular}

CC50: compound concentration that reduces cell viability by 50\%; MNCC: Maximum non-cytotoxic concentration; $\mathrm{EC}_{50}$ : compound concentration that reduces viral $\mathrm{CPE}$ by $50 \%$; SI: selectivity index 
The substitution on phenyl ring at C-2 position with electro withdrawing groups did not benefit the antiviral activity, but the activity is increased with a chlorine atom on C-7 in the quinazoline core. In the other hand, the incorporation of amines with saturated polar groups showed an increase of the activity (Figure 3).

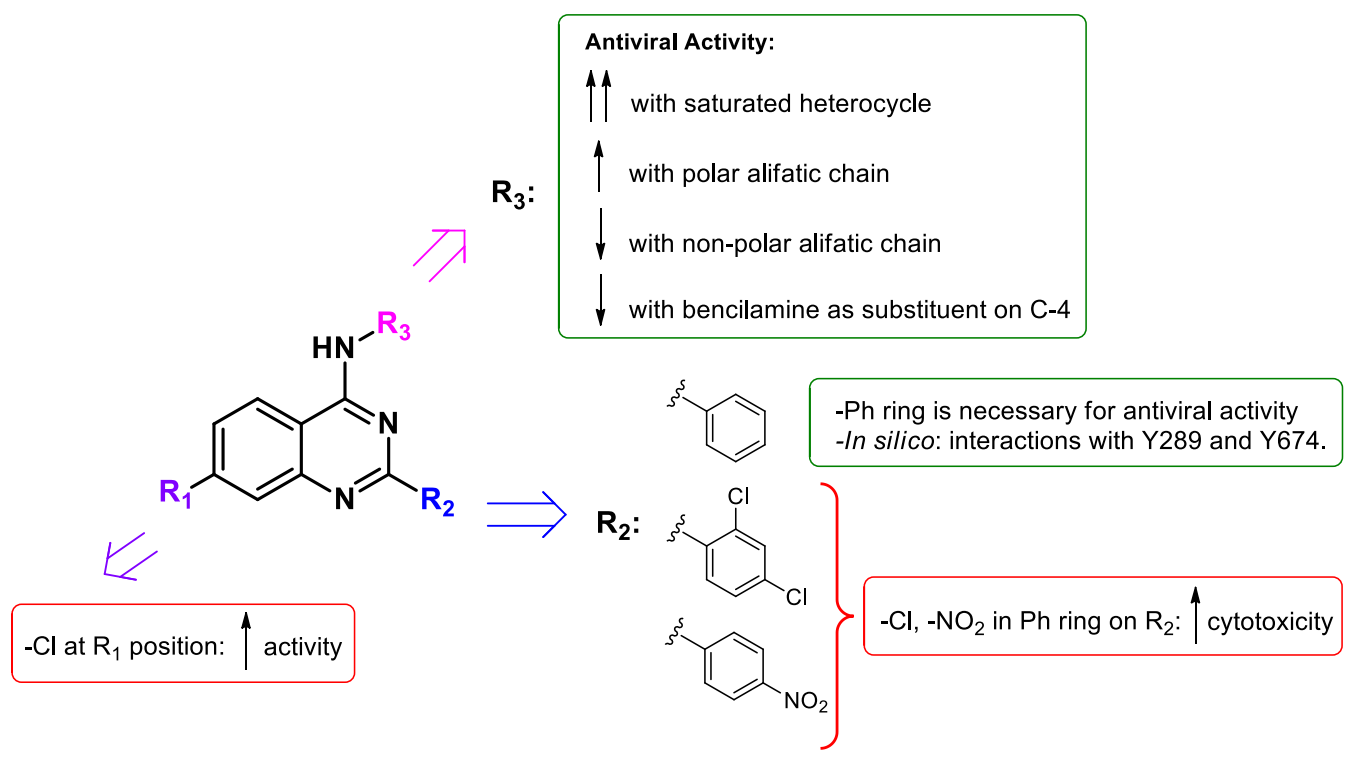

Figure 3. Highlights of structure-activity correlation.

\section{Physicochemical properties}

Compound 1.9 was selected for physicochemical studies in vitro, in terms of solubility and stability. The solubility (S) was evaluated at $\mathrm{pH} 1.2,6.8$, and 7.4 employing the shake flask method by UV spectroscopy [12]. The stability was tested in mouse and bovine plasma by HPLC-MS. The collected data are summarized in Table 2. Figure 3 shows the stability profile of $\mathbf{1 . 9}$.

Table 2. Experimental solubility and stability for compound 1.9.

\begin{tabular}{cccccc}
\hline \multicolumn{3}{c}{ Aqueous solubility $\left(\mu \mathrm{g} / \mathbf{m L}^{\mathbf{a}, \mathbf{b}}\right.$} & \multicolumn{2}{c}{ Stability $\left(\mathbf{t}_{1 / 2} \mathbf{m i n}\right)^{\mathbf{b}}$} \\
\hline Compound & SGF & SIF & PBS & Mouse Plasma & Bovine Plasma \\
\hline $\mathbf{1 . 9}$ & $8656.5 \pm 483.3$ & $420.4 \pm 23.7$ & $187.2 \pm 5.0$ & $>120$ & $>120$ \\
\hline
\end{tabular}

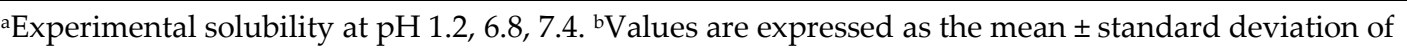
independent experiments run in triplicate.

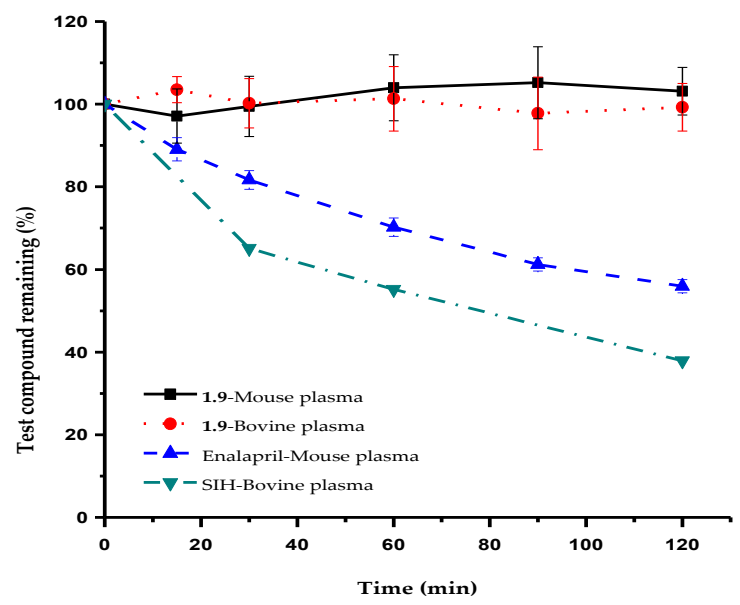

Figure 3. Stability profile of $\mathbf{1 . 9}$ in mouse and bovine plasma. The values represent mean percentage test compound remaining against time with the error bars representing the standard deviation of three separate experiments. 


\section{Conclusions}

From a series of twenty-seven derivates of $N$-(2-morpholinoethyl)-2-phenylquinazolin-4-amine (1), five compounds showed improved activity. One of them, 1.9, was tested in terms of solubility and stability and presented adequate solubility in different media and high stability profile in mouse and bovine plasma. Since these parameters are important for the development of oral drugs, it can be considered a promising candidate to treat BVDV infection and it encourages us to continue with further studies.

Funding: This work was supported by the Agencia Nacional de Promoción Científica y Tecnológica, Argentina (PICT 2014-1884, CONICET (PIP 201411220130100721 to MB), (PICT 2012-2867 and UBACYT 2014-2017 20920160100170BA to LVC).

Acknowledgments: GAF, DNF, RR and LB thank to CONICET for postdoctoral and doctoral fellowships.

Conflicts of Interest: The authors declare no conflict of interest.

\section{References}

1. Smith, D.B.; Meyers, G.; Bukh. J,; Gould, E.A.; Monath, T.; Muerhoff, A.S.; et.al. J. Gen. Virol. 2017, 98, 2106-2112. DOI: 10.1099/jgv.0.000873.

2. Mirosław, P.; Polak, M. BMC Veterinary Research 2019, 15, 278-289. DOI: 10.1186/s12917-019-2029-z.

3. Pecora, Andrea. Actualización en diarrea viral bovina, herramientas diagnósticas y estrategias de prevención. 1st ed. Ediciones INTA: Ciudad Autónoma de Buenos Aires, Argentina, 2017. Digital Book, ISBN 978-987-521-853-6.

4. Mittal, L.; Srivastava, M.; Asthana, S. J. Phys. Chem. B 2019, 123, 6150-6160. DOI: 10.1021/acs.jpcb.9b01859.

5. Castro, E.F.; Casal, J.J.; España de Marco, M.J.; Battini, L.; Fabiani, M.; Fernández, G. A., et. al. Bioorg. Med. Chem. Lett. 2019, 29, 262-266. DOI: 10.1016/j.bmcl.2018.11.041.

6. Bollini, M.; Bruno, A.M.; Niño, M.E.; Casal, J.J; Sasiambarrena, L.D.; Valdez, D.A.G., Battini, L.; Puente, V. R.; Lombardo, M.E. Med. Chem. 2019, 15 (3), 265-276. DOI: 10.2174/1573406414666181005145042.

7. Cheng, R.; Guo, T.; Zhang-Negrerie, D.; Du, Y.; Zhao, K. Synthesis (Germany) 2013, 45 (21), 2998-3006. DOI: 10.1055/s-0033-1338521.

8. Hour, M.J.; Huang, L.J.; Kuo, S.C.; Xia, Y.; Bastow, K.; Nakanishi, Y., Hamel, E.; Lee, K.-H. J. Med. Chem. 2000, 43, 4479-4487. DOI: 10.1021/jm000151c.

9. a) Nakamoto et. al. Patent: US 7,932,272 B2, 2011. b) Arnott, A.; Chan, L.C., Cox, B.G.; Meyrick, B., Phillips, A. J. Org. Chem. 2011, 76, 1653-1661. DOI: 10.1021/jo102262k.

10. a) Duan, H.; Lee, J. W.; Moon, S. W.; Arora, D.; Li, Y.; Lim, H.-Y.; Wang, W. J. Med. Chem. 2016, 59 (17), 7783-7800. DOI: 10.1021/acs.jmedchem.6b00041. b) Storz, T.; Heid, R.; Zeldis, J.; Hoagland, S.M.; Rapisardi, V., Hollywood, S., Morton, G. Org. Process Res. Dev. 2011, 15, 918-924. DOI: 10.1021/op1002352.

11. Kovaříková, P.; MrKvičková, Z.; Klimeš, J, J. Pharm. Biomed. Sci. 2008, 47, 360-370 DOI: 10.1016/j.jpba.2008.01.011

12. a) M. Bollini, J. Cisneros, K. Spasov, K.S. Anderson, W.L. Jorgensen. Bioorg. Med. Chem. Lett. 2013, 23 (18), 5213-5216. b) Sławinski, J.; Szafranski, K.; Pogorzelska, A.; Zołnowska, B.; Kawiak, A.; Macur, K., et. al. Eur. J. Med. Chem. 2017, 132, 236-248. DOI: 10.1016/j.ejmech.2017.03.039.

13. Jorgensen, W. L.; Duffy, E. M. Adv. Drug Deliv. Rev. 2002, 54, 355-366. DOI: 10.1016/S0169-409X(02)00008-X.

(C) 2019 by the authors. Submitted for possible open access publication under the terms and conditions of the Creative Commons Attribution (CC BY) license (http://creativecommons.org/licenses/by/4.0/). 